\title{
Genetic variability in the ITS and IGS regions of the ribosomal DNA of Acremonium cavaraeanum exhibiting antimicrobial activity
}

\author{
A.R. Todaro ${ }^{1}$, V.X. Nascimento ${ }^{1}$, N.C.C. Souza ${ }^{1}$, P.P. Silva ${ }^{1}$, J.M. Santos ${ }^{1}$, \\ E.A.V.F. Ramalho', T.V.C. Melo ${ }^{2}$ I.S.M. Silva², G.S. Lins Júnior ${ }^{2}$, \\ M.L.A. Bastos ${ }^{2}$, D.F. Farias ${ }^{3}$, P.C.V. Souza ${ }^{3}$, A.F.U. Carvalho ${ }^{3}$, \\ M.C.S. Silva ${ }^{4}$, R.M.R.G. Almeida ${ }^{4}$ and E. Ramalho Neto ${ }^{1}$ \\ ${ }^{1}$ Laboratório de Genética Molecular, Genômica e Proteômica, \\ Centro de Ciências Agrárias, Campus Delza Gitaí, \\ Universidade Federal de Alagoas, Rio Largo, AL, Brasil \\ ${ }^{2}$ Laboratório de Cuidado em Saúde, Escola de Enfermagem e Farmácia, \\ Campus A.C. Simões, Universidade Federal de Alagoas, Maceió, AL, Brasil \\ ${ }^{3}$ Departamento de Bioquímica e Biologia Molecular e Departamento de Biologia, \\ Universidade Federal do Ceará, Fortaleza, CE, Brasil \\ ${ }^{4}$ Laboratório de Gestão de Alimentos e Bebidas, Campus A.C. Simões, \\ Universidade Federal de Alagoas, Maceió, AL, Brasil
}

Corresponding author: A.R. Todaro

E-mail: a.todaro@gmail.com

Genet. Mol. Res. 12 (4): 6983-6995 (2013)

Received March 26, 2013

Accepted November 1, 2013

Published December 20, 2013

DOI http://dx.doi.org/10.4238/2013.December.20.1

\begin{abstract}
Endophytic microorganisms represent promising alternatives for obtaining new drugs of biotechnological importance. In this study, the endophytic species Acremonium cavaraeanum (A1a) isolated from Cocos nucifera was cultivated for the production of secondary metabolites, and its extracts and fractions were evaluated by the dilution method (MIC). The EtOAc extracts and $\mathrm{MeOH}$ fractions were tested against Gram-positive and -negative bacteria, and had an
\end{abstract}


MIC of $125 \mu \mathrm{g} / \mathrm{mL}$ when evaluated in the EtOAc extract (EBI). The EtOAc extract (EBII) had an MIC of $62.25 \mu \mathrm{g} / \mathrm{mL}$ for Staphylococcus aureus and an MIC between 125 and $250 \mu \mathrm{g} / \mathrm{mL}$ for Gram-negative bacteria. The methanolic fractions showed activity with MIC between 125 and $250 \mu \mathrm{g} / \mathrm{mL}$ for all bacteria tested. The IGS region of the rDNA repeat unit of genomic DNA was analyzed by PCR/RFLPs, including endonucleases PstI, BamHII, HinfI, and EcoRI. The physical maps showed different restriction sites for the 6 Acremonium sp isolates, and revealed 5 RFLP patterns. The results showed that isolates of the same Acremonium species exhibited variation in this specific region. The sequences of ITS1-5.8S-ITS2 regions were aligned by Clustal W using the neighbor joining method, which grouped the isolates into 5 distinct clusters. This study aimed to evaluate the genetic diversity of $A$. cavaraeanum crops exhibiting antibacterial activity. The results of this study indicate that different fungal genetic isolates have biotechnological potential for the production of active bio-compounds against several human pathogens.

Key words: PCR; ITS; IGS; Acremonium fungal endophy; Antimicrobial activity

\section{INTRODUCTION}

A major problem in the control of human pathogenic microorganisms is their great capacity to acquire and transfer resistance to many antibiotics. The indiscriminate use of antibiotics has led to a rapid increase in antibiotic resistance among microbes, which has increased the need to develop novel antimicrobial agents to fight various infectious diseases. Peptide antibiotics represent a novel class of therapeutic agents, and have been isolated from a wide variety of multi-cellular organisms (Ahmad at al., 2012). Moreover, the increasing resistance of cancer cells towards current anticancer drugs requires the development of anticancer agents with a new mode of action. Some antimicrobial peptides have become therapeutic candidates as new anticancer agents (Kang et al., 2012).

Endophytic filamentous fungi represent an important genetic resource for biotechnology. Today, scientific communities have become interested in bioprospecting these microorganisms, because of their potentially important secondary production of metabolites for various applications, particularly in the pharmaceutical and food industries. Novel antibiotics, immunosuppressant, and anticancer compounds are only a few examples of what has been found after the isolation, culture, purification, and characterization of certain endophytes in recent years (Strobel and Daisy, 2003).

Genetic methods show high sensitivity and specificity for identifying microorganisms, and may be used for classifying microbial strains in diverse hierarchical taxonomic levels. The $18 \mathrm{~S}$ and $28 \mathrm{~S}$ ribosomal genes, along with the internal transcribed spacer (ITS) and intergenic spacer (IGS) regions, are the sites that have been targeted in studies involving fungi. The information found in these sequences has been extensively used in population diversity and characterization studies (Smit et al., 1999; van Elsas et al., 2000; Schabereiter-Gurtner et 
al., 2001; Sterflinger and Prillinger 2001), identification and detection (Brookman et al., 2000; Redecker 2000; Abd-Elsalam et al., 2003; Wu et al., 2003; Abliz et al., 2004), typing (Sutar et al., 2004), and for the establishment of phylogenetic relationships (LoBuglio and Taylor, 1995; Peintne et al., 2003).

The present study aimed to investigate the potential production of antimicrobial extracts and fractions against human pathogenic bacteria, as well as to taxonomically characterize and establish the phylogenetic relationship of the filamentous fungi Acremonium sp. The evaluation of DNA polymorphisms by polymerase chain reaction (PCR)/RFLPs in the rDNA repeat unit might lead to the detection of repetitive DNA related to DNA sequences associated with specific strains.

\section{MATERIAL AND METHODS}

\section{Plant materials}

Geographical origin, year, and hosts of Acremonium sp strains used in this study are shown in Table 1.

\section{Table 1. Isolates of Acremonium sp, geographical origin, year, and hosts.}

\begin{tabular}{lllll}
\hline Isolates & Strains & Source & Year & Hosts \\
\hline A1a & Acremonium cavaraeanum & Maceió, AL & 2007 & Coconut leaf \\
A1b & Acremonium cavaraeanum & São Luiz do Quintude, AL & 2007 & Coconut leaf \\
A1c & Acremonium cavaraeanum & Neópolis, AL & 2007 & Coconut leaf \\
A2a & Acremonium strictum & Fortaleza, CE & 2007 & Coconut leaf/morpho \\
URM3531 & Acremonium strictum & Fungal collection, PE & 1994 & Corn seeds \\
URM4364 & Acremonium ochraceum & Fungal collection, PE & 2001 & Soil \\
\hline
\end{tabular}

\section{Morphological characterization}

Morphological characterization of endophytic fungal isolates according to a standard taxonomic key included the colony diameter, texture, and color, in addition to the dimensions and morphology of hyphae and conidia (Gams, 1971).

\section{Isolation of the endophytic fungus $A$. cavaraeanum}

A strain of $A$. cavaraeanum (Josevali) W. Gams (1971) was isolated from straw coconut infected by Camarotella acrocomiae. Infected straw was washed with water, and submerged in $75 \%$ ethanol for 10 min, and then washed 3 more times in sterile distilled water. The epidermis was removed with a sterile scalpel. After 3-day growth on PDA medium at $28^{\circ} \mathrm{C}$, the number of fungal colonies was counted, and 1 morphotype was isolated. The isolated fungi were transferred to another plate containing PDA, and incubated in the dark at $28^{\circ} \mathrm{C}$ for 7 to 10 days to isolate monosporic colonies. To obtain these colonies, the endophytic fungi were inoculated on PDA medium, $\mathrm{pH} 6.8$, at $28^{\circ} \mathrm{C}$ for 7 to 10 days. Using a sterile scalpel, the mycelium was collected and immersed in $5 \mathrm{~mL} 0.1 \%$ Tween 80 solution. The sample was then homogenized by using a sterile glass rod, filtered with a syringe into autoclaved glass 
wool, washed with $0.85 \% \mathrm{NaCl}$, and collected into a $15-\mathrm{mL}$ Falcon tube. The volume was increased to $14 \mathrm{~mL}$ with $0.85 \%$ saline. In a Neubauer chamber, the spores were counted and the suspension was diluted to $10^{6}$ to $10^{7}$ spores per $\mathrm{mL}$. A volume of $100-\mu \mathrm{L}$ spore solution was inoculated on Petri dishes and incubated at $28^{\circ} \mathrm{C}$. Endophytic fungus isolation was performed using the method described by Huang et al. (2001). When the spores germinated, we isolated the monosporic colonies, and transferred them to $500-\mathrm{mL}$ bottles containing $200 \mathrm{~mL}$ SDNY medium for subsequent DNA extraction.

\section{DNA purification}

For DNA extraction, approximately $50 \mathrm{mg}$ frozen mycelium was transferred to 1.5 $\mathrm{mL}$ sterile microtubes (Eppendorf) containing $500 \mu \mathrm{L}$ extraction buffer solution (1 M Tris$\mathrm{HCl}, 0.5 \mathrm{M}$ EDTA, $5 \mathrm{M} \mathrm{NaCl}$, and $20 \% \mathrm{SDS}$ ), followed by the addition of $350 \mu \mathrm{L}$ redistilled phenol. The solution was gently mixed. To this solution, $150 \mu \mathrm{L}$ chloroform/isoamyl alcohol (24:1) was added and the mixture was then carefully inverted ( 2 or 3 times) until the chloroform became visible at the bottom of the tube immediately after centrifugation at 10,000

$g$ for $80 \mathrm{~min}$. After transferring the supernatant (approximately $400 \mu \mathrm{L}$ ) to a fresh $1.5-\mathrm{mL}$ Eppendorf tube, $25 \mu \mathrm{L} 10 \mathrm{mg} / \mathrm{mL}$ RNAase A solution was added. The DNA was then left at $37^{\circ} \mathrm{C}$ for $30 \mathrm{~min}$ to ensure complete RNA digestion. The next step involved the addition of 1 volume chloroform and centrifugation for $15 \mathrm{~min}$. The supernatant was transferred to a fresh tube, and $50 \%$ isopropyl alcohol was added, followed by a second round of centrifugation for $5 \mathrm{~min}$ at $10,000 \mathrm{~g}$. The supernatant was discarded. The pellet was washed twice with $1 \mathrm{~mL}$ $70 \%$ ethanol at $4{ }^{\circ} \mathrm{C}$. DNA was air dried for $30 \mathrm{~min}$ at room temperature and resuspended in $50 \mu \mathrm{L}$ TE buffer (10 mM Tris, $1 \mathrm{mM}$ EDTA, $\mathrm{pH}$ 8.0). DNA quantification was performed and stored at $4^{\circ} \mathrm{C}$. The protocol for DNA extraction was based on the methodology developed by Raeder and Broda (1985).

\section{ITS-rDNA amplification and sequence analysis}

For ITS1 amplification, the following primers were used: ITS5 (5'-GCAAGTAAAA GTCGTAACAAGG-3') and ITS2 and ITS4 (5'-TCCTCCGCTTATTGATATGC-3') (White et al., 1990). A thermal cycler for PCR (Applied Biosystems Veriti ${ }^{\mathrm{TM}}$ 96-Well Termal Cycler) was employed. The PCR products were separated by running $5 \mu \mathrm{L}$ PCR mixture on $1.5 \%$ (w/v) agarose gel, and staining the bands with ethidium bromide. For identification, the PCR products were purified using purification kits (ABI PRISM BigDye ${ }^{\mathrm{TM}}$ Terminator Cycle Sequencing Kits), and sequenced using the primer pair ITS5 and ITS4 on the ABI PRISM 3730XL Analyzer (96 capillary type). Then, the sequences were run by the Basic Local Alignment Search Tool (BLAST) $n$ program against the NCBI database (National Center for Biotechnology Information website), and were submitted to GenBank, where the accession number (Table 2) was obtained.

\section{Phylogenetic analyses}

Sequences were compared with the ITS1-5.8S-ITS2 of the rDNA sequence data from strains available at the public GenBank databases (http://www.ncbi.nem.nih.gov) by the 
BLAST $n$ sequence match routines. The sequences were aligned using the CLUSTAL W program (Thompson et al., 1994) and phylogenetic and molecular evolutionary analyses were conducted using MEGA version 4.1 (Tamura et al., 2007). The Kimura 2-parameter model (Kimura, 1980) was used to estimate evolutionary distance. Phylogenetic reconstruction was completed using the neighbor-joining (NJ) algorithm, with bootstrap values calculated from 1000 replicate runs, using the software routines in the MEGA software.

Table 2. Endophytic Acremonium isolates based on BLAST analysis and morphological identification.

\begin{tabular}{lclcl}
\hline Fungal strain & GenBank accession No. & Closest related species & Percentage similarity & Macro- and microscopic identification \\
\hline A1a & HQ644332 & Acremonium sp & 100.0 & Acremonium cavaraeanum \\
A1b & JF912333 & Acremonium sp & 100.0 & Acremonium cavaraeanum \\
A1c & JF912334 & Acremonium sp & 100.0 & Acremonium cavaraeanum \\
A2a & JF912337 & Acremonium strictum & 100.0 & Acremonium strictum \\
URM4364 & JF912335 & Acremonium sp & 100.0 & Acremonium cavaraeanum \\
URM3531 & JF912336 & Acremonium zeae & 100.0 & Acremonium strictum \\
\hline
\end{tabular}

\section{Culture conditions and preparation of extracts for the antimicrobial assay}

The strain A. cavaraeanum (A1a) was cultivated in PD for $15-30$ days at $25^{\circ} \mathrm{C}$. Ethyl acetate was added to the liquid culture at a 2:1 ratio. The liquid fungal extract was evaporated to obtain the crude extract, and the methanolic fractions were obtained by Sephadex- $\mathrm{H}_{2} \mathrm{O}$ chromatography. A quantity of $2 \mathrm{mg}$ of each crude extract and fractions were solubilized in $10 \%$ DMSO, in which a stock concentration of $2000 \mathrm{mg} / \mathrm{mL}$ was found.

\section{Antimicrobial assay: minimum inhibitory concentration (MIC) test}

The fungal extracts and methanolic fraction were screened for antimicrobial activity against the following bacteria: Staphylococcus aureus (ATCC 25923), Staphylococcus epidermidis (ATCC 12228), Salmonella typhimurim (ATCC 14028), Proteus mirabilis (ATCC 25933), Klebsiella pneumoniae (ATCC 13883), Pseudomonas aeruginosa (ATCC 27853), Escherichia coli (ATCC 25922), and yeast Candida albicans (ATCC 10231). Inoculum for the assays was prepared by diluting the scraped cell mass in $0.85 \% \mathrm{NaCl}$ solution, which was adjusted to the $0.5 \mathrm{McFarland}$ standard, and confirmed by spectrophotometry at 600 $\mathrm{nm}$. Cell suspensions were finally diluted to $5 \times 10^{5}$ cells $/ \mathrm{mL}$. Antibacterial activity was assessed using microbroth dilution assay on 96-well microplates according to the National Committee for Clinical Laboratory Standards approved document M7-A6 (NCCLS, 2003), using Brain Heart Infusion Broth on a tissue culture test plate (96 wells). The stock solutions of the fungal extracts were diluted and transferred to the first well, and serial dilutions were performed to obtain concentrations in the range of $1.0-0.156 \mathrm{mg} / \mathrm{mL}$. Gentamicin and ciprofloxacin were used as positive controls. The inoculum was added to all wells, and the plates were incubated for $48 \mathrm{~h}$ at $35^{\circ} \mathrm{C}$ for bacteria and $28^{\circ} \mathrm{C}$ for yeast. Antimicrobial activity was detected by adding $20 \mu \mathrm{L} 0.5 \%$ triphenyltetrazolium chloride (TTC, Merck) aqueous solution. MIC was defined as the lowest concentration of oil that inhibited visible growth, as indicated by TCC staining (dead cells are not stained by TTC). Each test was performed in triplicate. 


\section{Bioactivity against non-target model organisms}

To evaluate the toxicity of $A$. cavaraeanum bioactive extract on aquatic non-target animals, the toxicity model Artemia sp was assayed, following the methodology described in Carvalho et al. (1988). In brief, 10 Artemia sp nauplii were placed in different concentrations of the extracts $(10-1000 \mu \mathrm{g} / \mathrm{mL})$, in triplicate. After $24 \mathrm{~h}$, the animals were counted, and the mortality data were analyzed using probit (Finney, 1971) to estimate the $50 \%$ lethal concentration $\left(\mathrm{LC}_{50}\right)$, which is the concentration capable of causing $50 \%$ death of brine shrimp nauplii.

Another test to investigate the toxicity effects of $A$. cavaraeanum on non-target organisms was assessed using Rockfeller strain Aedes aegypti larvae, which were supplied by the mosquito colony maintained at NUVET/SESA (Núcleo de Controle de Endemias Transmissíveis por Vetores - Secretaria de Saúde do Estado do Ceará, Brazil). Separate tests were run for larvae and pupae, according to methodology described by Farias et al. (2009). Bioassays were performed with 3rd-instar larvae and pupae of $A$. aegypti, which were collected with a Pasteur pipette, placed on filter paper for the removal of excess water, and transferred (20 per test) with a tiny brush to 150 -mL disposable plastic cups containing $10 \mathrm{~mL}$ A. cavaraeanum bioactive extract $(500 \mu \mathrm{g} / \mathrm{mL})$ and the solutions were diluted $(1: 2 ; 1: 4 ; 1: 8 ; 1: 10 ; \mathrm{v} / \mathrm{v})$ as required. Larvae were maintained at room temperature, and mortality/survival registered after $24 \mathrm{~h}$. The experiments were run in triplicate for each sample, and distilled water was used as a negative control. The larvae were considered dead when no movement was detected after they were probed with a tiny brush. Mortality data were subjected to probit analysis (Finney, 1971) to estimate the median lethal concentration against the larvae and pupae of $A$. aegypti $\left(\mathrm{LC}_{50}\right)$. The dose-response relationship was determined using probit analysis (Finney, 1971). The regression equation was determined by linear regression, using the Statplus ${ }^{\circledR}$ program.

\section{RESULTS}

\section{Molecular taxonomic characterization and phylogenetic analyses}

The molecular and phylogenetic analysis data were used for the taxonomic characterization of filamentous endophytic fungi isolated from Cocos nucifera infected by the pathogen C. acrocomiae. ITS1-5.8S-ITS2 partial sequences of the strains were compared to ITS sequences from organisms represented in the GenBank database. The highest score sequences were recovered from the databases, and aligned with the ITS sequences of the endophytic fungi obtained from C. nucifera. The alignments (about $480 \mathrm{nt}$ ) were used to calculate distance matrices, and generate phylogenetic trees (Figure 1), as previously described (see Material and Methods, Phylogenetic analyses).

\section{Physical maps of the IGS region generated by RFLPs using restriction endonucleases}

The potential of the IGS region for studying the intraspecific variability of Acremonium sp population was evaluated by RFLP analysis. The IGS region was amplified by PCR, and produced a DNA fragment of approximately $2163 \mathrm{bp}$ for $A$. cavaraeanum (isolates A1a, A1b, A1c, and URM4364), 2427 bp for Acremonium strictum (isolate A2a), and 2211 bp for Acremonium zeae (isolate URM3531). 


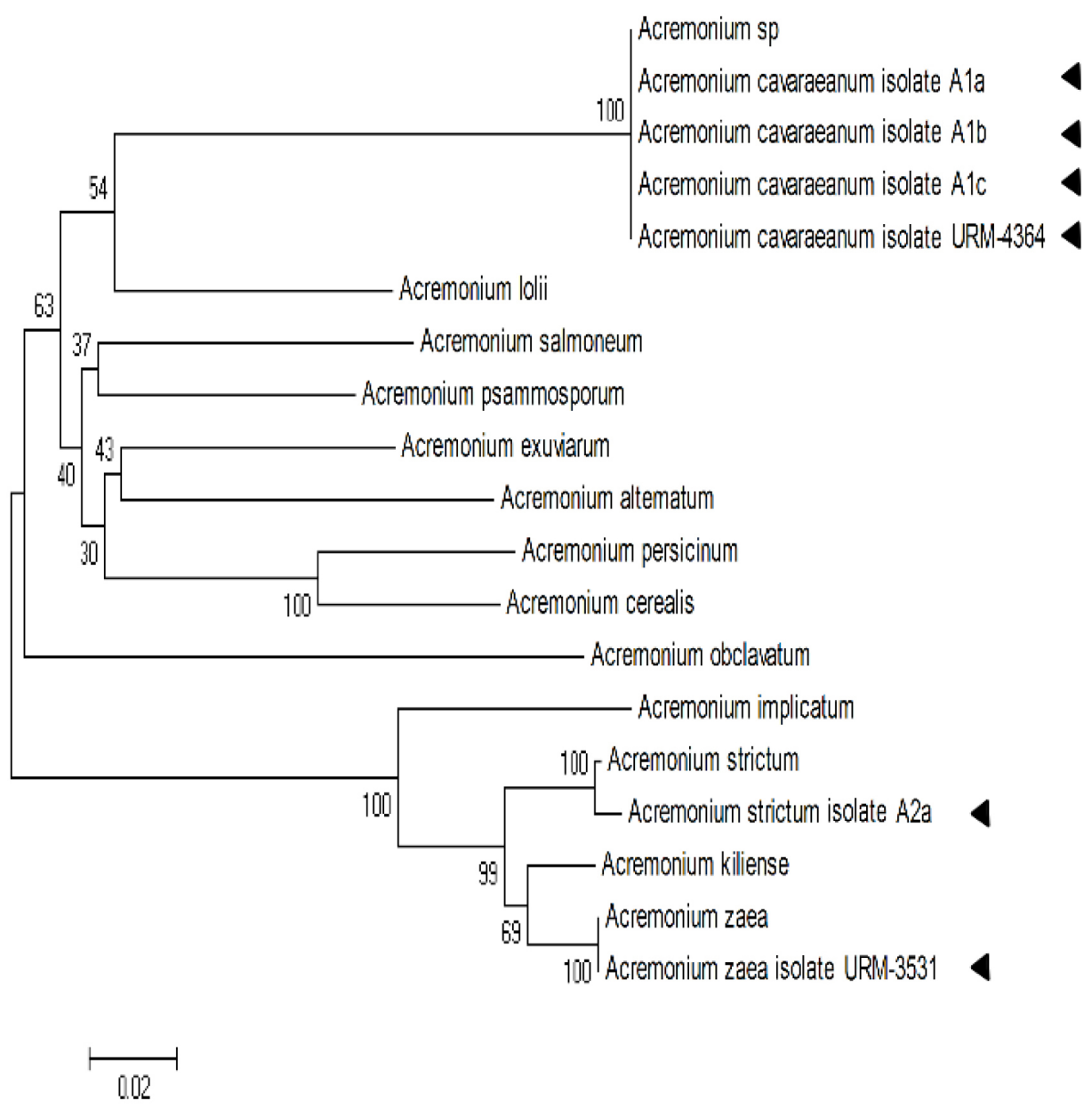

Figure 1. Dendrogram showing the genetic diversity of Acremonium sp isolates and the relationship between genus and species based on specific ITS1/ITS2 region. The analysis was based on the neighbor joining algorithm. Isolates obtained in this study are represented by filled triangles. The other isolates were taken from GenBank.

The results obtained from the RFLP analysis of the IGS region using the endonucleases PstI, BamHI, HinfI, and EcoRI showed that there was genetic variability among the isolates tested (Figures 2 and 3 ). The single and double digestions with all enzymes revealed 3 different physical maps, i.e., 3 characteristic RFLP patterns. Isolates A1a and URM4364 generated identical physical maps, with this molecular marker characterizing them as probably being the same species. The other 2 isolates, A1b and A1c, were different to each other, and were also different to A1a, according to the DNA patterns generated by IGS digestion with the endonucleases used in this study (Figure 2).

The IGS analysis also revealed a different electrophoretic pattern for isolate A2a. This particular genotype produced a diverse physical map compared to the maps generated by A1a, A1b, A1c, and URM4364 (Figure 3). 

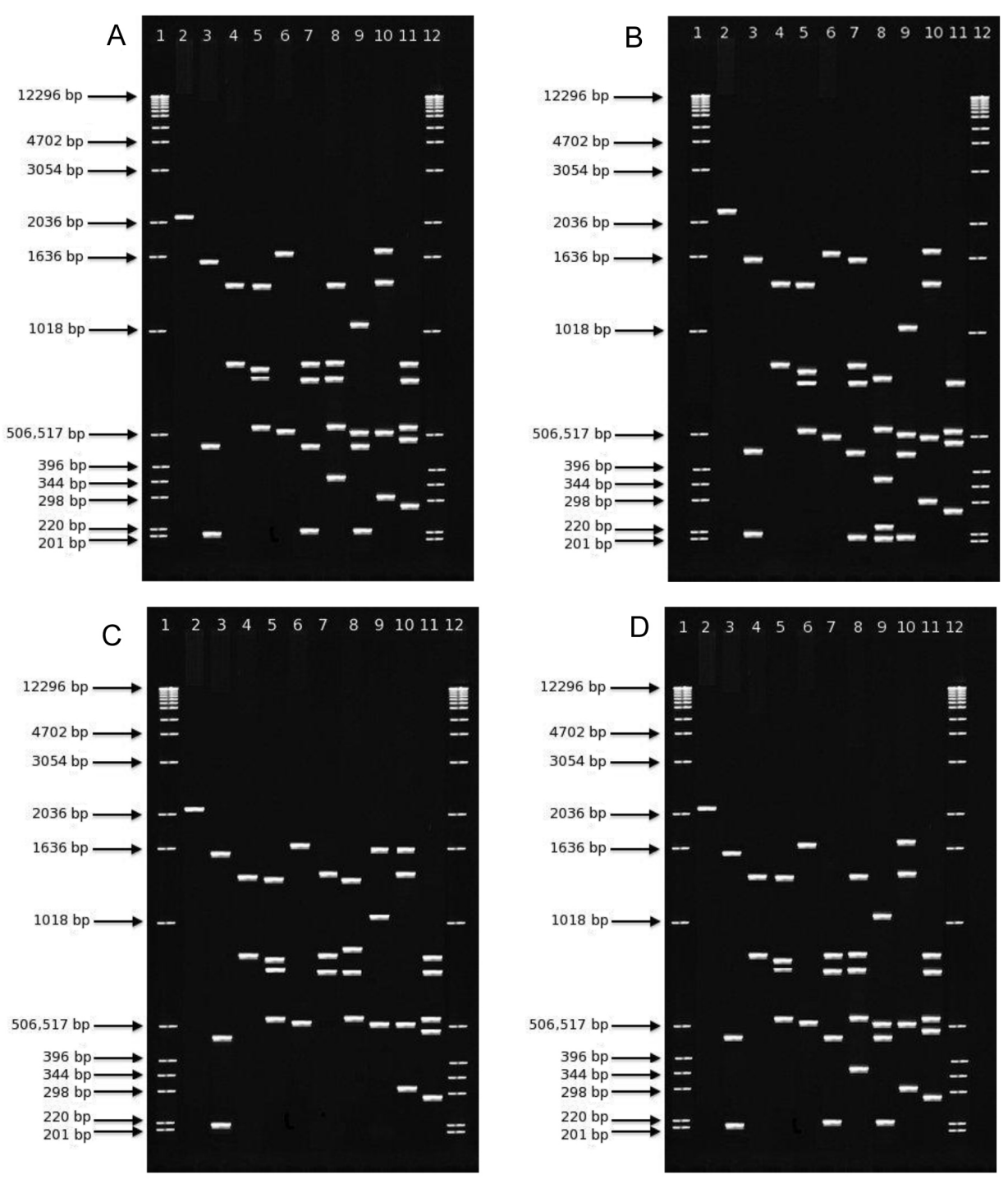

Figure 2. Single and double digestions of the IGS region of the isolates: A. A1a, B. A1b, C. A1c, and D. URM4364. The PCR products were run on $1.5 \%$ agarose gel stained with ethidium bromide. Lane $1=1$-kb ladder; lane $2=$ control; lane $3=$ Pst $;$ lane $4=$ BamHI; lane $5=$ HinfI; lane $6=$ EcoRI; lane $7=$ Pst $/$ Bam $\mathrm{HI}$; lane $8=$ PstI $/$ HinfI; lane $9=$ Pst $/$ EcoRI; lane $10=E c o \mathrm{RI} /$ Bam $\mathrm{HI}$; lane $11=$ EcoRI/HinfI; lane $12=1-\mathrm{kb}$ ladder.

\section{Genetic diversity of Acremonium sp isolates by sequencing the ITS region of 5.8S ribosomal DNA}

Three independent PCRs were performed for each isolate isolated from Acremonium sp to detect and confirm mutations. The ITS rDNA sequences of 6 isolates obtained with primer ITS4 were compared to other sequences deposited in the GenBank. The nucleotide 
sequence analysis of 6 Acremonium sp isolates revealed 6 nucleotide variations in relation to specific reference sequences. To date, the nucleotide variations of this Acremonium species based on the nucleotide sequences of the 5.8S ITS region of ribosomal DNA have not been described by other authors.

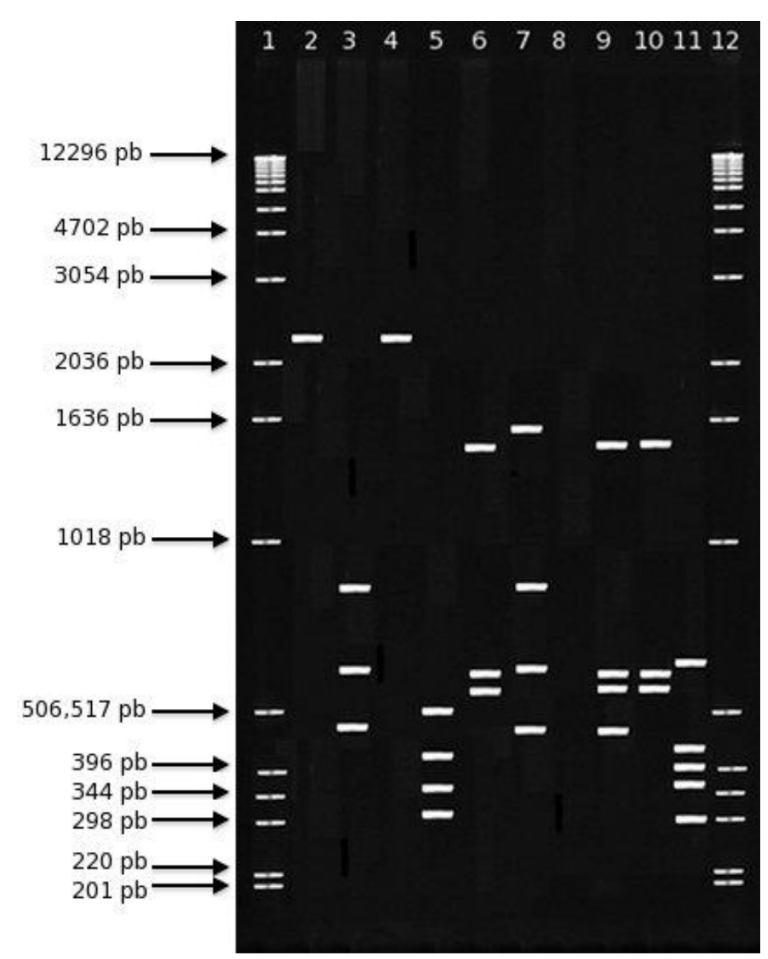

Figure 3. Single and double digestions of the IGS region of isolated A2a. The PCR products were run on $1.5 \%$ agarose gel stained with ethidium bromide. Lanes $1=1-\mathrm{kb}$ ladder; lane $2=\mathrm{control}$; lane $3=$ Pst $\mathrm{I}$; lane $4=$ Bam HI; lane $5=$ HinfI; lane $6=$ EcoRI; lane $7=$ Pst $\mathrm{I} /$ Bam HI; lane $8=$ Pst $\mathrm{I} /$ HinfI; lane $9=$ PstI $/$ EcoRI; lane $10=$ EcoRI/ BamHI; lane $11=$ EcoRI/HinfI; lane 12 = 1-kb ladder.

\section{Antimicrobial activity}

The antimicrobial activity of fungal EtOAc extracts and $\mathrm{MeOH}$ fractions derived from cultures of $A$. cavaraeanum (Ala) by the dilution method showed activity against standard strains, Gram-positive $S$. aureus and $S$. epidermidis, Gram-negative S. typhimurim, P. mirabilis, K. pneumoniae, P. aeruginosa, and E. coli. The crude extracts (EBI and EBII) showed activity with MIC between 125 and $250 \mu \mathrm{g} / \mathrm{mL}$ for Gram-negative bacteria. The Gram-positive bacterium S. aureus had the lowest MIC observed $(62.5 \mu \mathrm{g} / \mathrm{mL})$ (Table 3). The $\mathrm{MeOH}$ fractions used for both Gram-positive and -negative bacteria also had MICs of between 125 and $250 \mu \mathrm{g} / \mathrm{mL}$. In comparison, the crude EtOAc extract of $A$. cavaraeanum did not cause significant mortality to A. aegypti larvae or Artmeia sp nauplii, even at high concentrations of 500 and $1000 \mu \mathrm{g} / \mathrm{mL}$, respectively (Table 4). 
Table 3. Antimicrobial and antifungal activity of EtOAc extract and $\mathrm{MeOH}$ fractions of Acremonium cavaraeanum (A1a).

\begin{tabular}{lccccc}
\hline Microorganisms & \multicolumn{4}{c}{ Minimum inhibited concentration $(\mu \mathrm{g} / \mathrm{mL})$} \\
\cline { 2 - 6 } & $\begin{array}{c}\text { EBI (A1a) } \\
\text { (EtOAc) }\end{array}$ & $\begin{array}{c}\text { EBII (A1b) } \\
\text { (EtOAc) }\end{array}$ & $\begin{array}{c}\text { MF5 (EBI) } \\
\text { A1a }\end{array}$ & $\begin{array}{c}\text { MF6 (EBII) } \\
\text { A1b }\end{array}$ & MF7 (EBII) \\
A1b
\end{tabular}

Concentrations: $1000=$ not active; $500-250=$ active; 125 to $15.6=$ very active. $\mathrm{Nt}=$ not tested. Control $=$ positive control strains in culture medium: $(+)=$ no growth inhibition.

\begin{tabular}{|c|c|c|c|}
\hline Non-target model organism & Concentration $(\mu \mathrm{g} / \mathrm{mL})$ & Mortality (\%) & $\mathrm{LC}_{50}(\mu \mathrm{g} / \mathrm{mL})$ \\
\hline Aedes aegypti & 500 & 0.0 & $>500$ \\
\hline Artemia sp & 1000 & 26.7 & $>1000$ \\
\hline
\end{tabular}

\section{DISCUSSION}

Endophytic microorganisms are a group of organisms that are able to produce secondary metabolites that are of high interest for pharmaceutical applications because of their biological activity. Endophytic microorganisms represent an important genetic resource for biotechnology and have been the target of many ecological and taxonomic studies. Despite the environmental and biotechnological importance of fungi, most of these organisms remain uncharacterized, with limited knowledge about the evolutionary relationships of many taxa (Sette et al., 2005).

The 531-bp sequences from the ITS1/ITS2 of the A. cavaraeanum isolates (A1b, A1c and URM4364) revealed a deletion of 1 adenine (A), which led to the deletion of 1 alanine (Ala); thus, modifying the amino acid composition of these isolates. The 486-bp sequence obtained from A. strictum (A2a) showed the deletion of $1 \mathrm{~A}$, an insertion of 1 guanine (G), 2 A replaced by $1 \mathrm{~T}$ (T-A), and $1 \mathrm{G}$ replaced by $1 \mathrm{~A}(\mathrm{~A}-\mathrm{G})$. All of these nucleotide changes generated significant changes in the amino acid composition of this isolate. There were 2 deletions, Ala and T (Thr), and 2 insertions of glycine (Gly). The 477-bp sequence analysis of A. zeae revealed 1 deletion of A, which led to the deletion of 1 Ala. The regions in the genome (locus), where this variability occurs, are termed polymorphic, with variability occurring by the insertion, deletion, or replacement of 1 or more base pairs in both the exons and introns, or other non-coding regions.

The rDNA repeat unit contains highly conserved DNA sequences $(18 \mathrm{~S}, 28 \mathrm{~S}$, and $5.8 \mathrm{~S}$ rRNA genes). As a result, it has been used to clarify phylogenetic relationships among genera 
and species, as well as regions of variable sequences (IGS and ITS) that are used to detect genetic variation among fungal species or strains of the same species (White et al., 1990). The IGS and ITS regions accumulate genetic variability, and are widely used for differentiating species or strains of the same species.

The ITS region in this study was PCR amplified and sequenced with the aim of studying the genetic distance within an Acremonium sp population. The sequences analyzed by the BLAST $n$ computational tool (which compares the sequences submitted for analysis with sequences stored in the GenBank) were found to have high homology with different Acremonium species.

Phylogenetic analysis was performed using sequences of the ITS 480-bp fragment from 19 isolates, of which 6 isolates were from this study and 13 were from the GenBank. Phylogenetic trees were reconstructed by the NJ method using the Mega 4.1 software (Tamura et al., 2007). The reliability of the tree was evaluated by analysis of 1000 replicates.

Sequences were aligned using BLAST (Altschul et al., 1997), followed by the multiple alignment tool CLUSTAL W (Thompson et al., 1994).

The distance matrices were calculated using the parameter K-2-P, which fixes multiple hits considering the rates of transitional substitutions and transversions between sites. Gaps and undetermined $\mathrm{N}$ bases were treated as complete deletions. Nucleotides, "missing data", "alignment gap", and "identical symbols" were coded as (N), (-), and (.), respectively.

The antibacterial activity of crude extracts and fractions from endophytic fungi $\mathrm{A}$. $\mathrm{Ca}$ varaeanum (A1a) were screened for their antibacterial activities against the standard ATCC bacterial strains. In this study, EtOAc extracts and $\mathrm{MeOH}$ fractions showed antimicrobial activity against Gram-positive and -negative bacteria (Table 3). The results were clinically relevant, particularly considering the resistance of pathogens to existing antibiotics. The brine shrimp lethality test is used to evaluate the presence of bioactivity in biological samples, particularly in research for antiproliferative compounds. However, the lack of $A$. cavaraeanum (A1a) EtOAc extract activity in this study indicates major specificity of this species against fungi (CostaLotufo et al., 2005). A similar result was observed in the larvicidal activity test, in which the sample did not present activity against $A$. aegypti larvae. The data showed a limited spectrum of activity against non-target organisms. The biological activity of samples of different origin against $A$. aegypti is common, reinforcing the major absence of $A$. cavaraeanum (A1a) EtOAc extract activity on non-target model organisms (Ferreira et al., 2009; Farias et al., 2010).

Artemia sp is one of the most valuable test organisms available for ecotoxicity testing. The cyst-based toxicity assay employed is cheap, simple and reliable, being capable to provide important answers to routine needs of toxicity screening. Artemia sp can be used alone, as a single test species, or combined with several other invertebrates (Nunes et al., 2006). This is a helpful approach for detecting acute effects of novel compounds on non-target organisms. In addition, this test has been employed in parallel to cytotoxicity assays using healthy human cells (e.g., hemolytic, cell viability, etc.) in order to gather preliminary information on non-specific effects of novel bioactive samples (Costa-Lotufo et al., 2005; Farias et al., 2010; Ferreira et al., 2011). Based on the results generated by the Artemia-based test, it is possible to say preliminarily that the A. cavaraeanum (A1a) EtOAc extract does not show potential ecological risk, since it did not present toxic acute effects on Artemia sp nauplii nor against A. aegypti larvae. The result obtained with Artemia nauplii also showed that $A$. cavaraeanum (A1a) EtOAc extract is potentially not toxic to non-fungal cells. Nevertheless, to fully confirm the lack of deleterious effects of $A$. cavaraeanum (A1a) EtOAc extract on non-target cells or organisms further experimentation should be done. 
Based on the data generated by RFLPs and DNA sequencing of IGS and ITS/rDNA repeat units, isolates A1a and URM4364 generated identical physical maps, characterizing them as probably being the same species, at least according to this molecular marker. The results also showed that the 2 other isolates A1b and A1c differ from each other and also from A1a.

Although not all Acremonium isolates were tested for biological activity, the isolate (A1a) was used in all bioactivity tests (bacteria: S. aureus, S. epidermidis, S. typhimurim, $P$. mirabilis, $K$. pneumoniae, $P$. aeruginosa, E. coli; and yeast: $C$. albicans), and proved to be capable of effectively reducing pathogen growing when the system was based on dilutions of 62.5 and $250 \mu \mathrm{g} / \mathrm{mL}$ crude extracts and $\mathrm{MeOH}$ fractions.

\section{REFERENCES}

Abd-Elsalam K, Aly IN, Abdel-Satar MA, Khalil MS, et al. (2003). PCR identification of Fusarium genus on nuclearribosomal-DNA sequence data. Afr. J. Biotechnol. 2: 82-85.

Abliz P, Fukushima K, Takizawa K and Nishimura K (2004). Identification of pathogenic dematiaceous fungi and related taxa based on large subunit ribosomal DNA D1/D2 domain sequence analysis. FEMS Immunol. Med. Microbiol. 40: 41-49.

Ahmad A, Ahmad E, Rabbani G, Haque S, et al. (2012). Identification and design of antimicrobial peptides for therapeutic applications. Curr. Protein Pept. Sci. 13: 211-223.

Altschul SF, Madden TL, Schaffer AA, Zhang J, et al. (1997). Gapped BLAST and PSI-BLAST: a new generation of protein database search programs. Nucleic Acids Res. 25: 3389-3402.

Brookman JL, Mennim G, Trinci AP, Theodorou MK, et al. (2000). Identification and characterization of anaerobic gut fungi using molecular methodologies based on ribosomal ITS1 and 185 rRNA. Microbiology 146 (Pt 2): 393-403.

Carvalho AFU, Melo VMM, Aguiar LMBA and Matos FJA (1988). Avaliação da toxicidade de extratos de plantas medicinais através de bioensaio com Artemia salina leach. Ciênc. Cult. 40: 1109-1111.

Costa-Lotufo LV, Khan MT, Ather A, Wilke DV, et al. (2005). Studies of the anticancer potential of plants used in Bangladeshi folk medicine. J. Ethnopharmacol. 99: 21-30.

Farias DF, Cavalheiro MG, Viana SM, De Lima GP, et al. (2009). Insecticidal action of sodium anacardate from Brazilian cashew nut shell liquid against Aedes aegypti. J. Am. Mosq. Control. Assoc. 25: 386-389.

Farias DF, Cavalheiro MG, Viana MP, Queiroz VA, et al. (2010). Water extracts of Brazilian leguminous seeds as rich sources of larvicidal compounds against Aedes aegypti L. An. Acad. Bras. Cienc. 82: 585-594.

Ferreira PM, Carvalho AF, Farias DF, Cariolano NG, et al. (2009). Larvicidal activity of the water extract of Moringa oleifera seeds against Aedes aegypti and its toxicity upon laboratory animals. An. Acad. Bras. Cienc. 81: 207-216.

Ferreira PM, Farias DF, Viana MP, Souza TM, et al. (2011). Study of the antiproliferative potential of seed extracts from Northeastern Brazilian plants. An. Acad. Bras. Cienc. 83: 1045-1058.

Finney DJ (1971). Probit Analysis. 3rd edn. Cambridge University Press, Cambridge.

Gams W (1971). Cephalosporium-artige Schimmelpilze (Hyphomycetes). Gustav Fischer Verlag, Stuttgart.

Huang Y, Wang J, Li G, Zheng Z, et al. (2001). Antitumor and antifungal activities in endophytic fungi isolated from pharmaceutical plants Taxus mairei, Cephalatasux fortunei and Torreya grandis. FEMS Immunol. Med. Microbiol. 31: 163-167.

Kang SJ, Ji HY and Lee BJ (2012). Anticancer activity of undecapeptide analogues derived from antimicrobial peptide, brevinin-1EMa. Arch. Pharm. Res. 35: 791-799.

Kimura M (1980). A simple method for estimating evolutionary rates of base substitutions through comparative studies of nucleotide sequences. J. Mol. Evol. 16: 111-120.

LoBuglio KF and Taylor JW (1995). Phylogeny and PCR identification of the human pathogenic fungus Penicillium marneffei. J. Clin. Microbiol. 33: 85-89.

National Committee for Clinical Laboratory Standards (NCCLS) (2003). Methods for Dilution Antimicrobial Susceptibility Tests for Bacteria that Grow Aerobically. Documents M7-A6 and M100-S13, Pennsylvania.

Nunes BS, Carvalho FD, Guilhermino LM and Van Stappen G (2006). Use of the genus Artemia in ecotoxicity testing. Environ. Pollut. 144: 453-462.

Peintner U, Moser MM, Thomas KA and Manimohan P (2003). First records of ectomycorrhizal Cortinarius species (Agaricales, Basidiomycetes) from tropical India and their phylogenetic position based on rDNA ITS sequences. Mycol. Res. 107: 485-494.

Raeder U and Broda P (1985). Rapid preparation of DNA from filamentous fungi. Lett. Appl. Microbiol. 1: 17-20. 
Redecker D (2000). Specific PCR primers to identify arbuscular mycorrhizal fungi within colonized roots. Mycorrhiza 10: $73-80$.

Schabereiter-Gurtner C, Pinar G, Lubitz W and Rolleke S (2001). An advanced molecular strategy to identify bacterial communities on art objects. J. Microbiol. Methods 45: 77-87.

Sette LD, de Oliveira VM and Manfio GP (2005). Isolation and characterization of alachlor-degrading actinomycetes from soil. Antonie Van Leeuwenhoek 87: 81-89.

Smit E, Leeflang P, Glandorf B, van Elsas JD, et al. (1999). Analysis of fungal diversity in the wheat rhizosphere by sequencing of cloned PCR-amplified genes encoding $18 \mathrm{~S}$ rRNA and temperature gradient gel electrophoresis. Appl. Environ. Microbiol. 65: 2614-2621.

Sterflinger K and Prillinger H (2001). Molecular taxonomy and biodiversity of rock fungal communities in an urban environment (Vienna, Austria). Antonie Van Leeuwenhoek 80: 275-286.

Strobel G and Daisy B (2003). Bioprospecting for microbial endophytes and their natural products. Microbiol. Mol. Biol. Rev. 67: 491-502.

Sutar R, David JK, Ganesan K, Ghosh AK, et al. (2004). Comparison of ITS and IGS1 regions for strain typing of clinical and non-clinical isolates of Pichia anomala. J. Med. Microbiol. 53: 119-123.

Tamura K, Dudley J, Nei M and Kumar S (2007). MEGA4: Molecular Evolutionary Genetics Analysis (MEGA) software version 4.0. Mol. Biol. Evol. 24: 1596-1599.

Thompson JD, Higgins DG and Gibson TJ (1994). CLUSTAL W: improving the sensitivity of progressive multiple sequence alignment through sequence weighting, position-specific gap penalties and weight matrix choice. Nucleic Acids Res. 22: 4673-4680.

van Elsas JD, Duarte GF, Keijzer-Wolters A and Smit E (2000). Analysis of the dynamics of fungal communities in soil via fungal-specific PCR of soil DNA followed by denaturing gradient gel electrophoresis. J. Microbiol. Methods 43: 133-151.

White TJ, Bruns T, Lee S and Taylor J (1990). Amplification and Direct Sequencing of Fungal Ribosomal RNA Genes for Phylogenetics. In: PCR Protocols: A Guide to Methods and Applications (Innis MA, Gelfand DH, Shinsky JJ and White TJ, eds.). Academic Press, San Diego, 315-322.

Wu Z, Tsumura Y, Blomquist G and Wang XR (2003). 18S rRNA gene variation among common airborne fungi, and development of specific oligonucleotide probes for the detection of fungal isolates. Appl. Environ. Microbiol. 69: 5389-5397. 